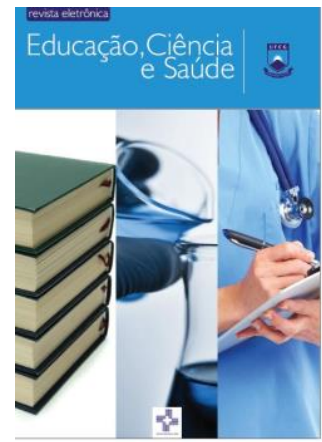

EDUCAÇÃO CIÊNCIA E SAÚDE

http://dx.doi.org/10.20438/ecs.v5i2.147

\title{
AS POSSIBILIDADES DA MONITORIA PARA A FORMAÇÃO DOCENTE: UM RELATO DE EXPERIÊNCIA NO CURSO DE CIÊNCIAS BIOLÓGICAS
}

\author{
Meris de Oliveira Silva ${ }^{1}$, Cícera Firmina da Silva ${ }^{1}$, Edinalva Alves Vital dos \\ Santos ${ }^{2}$ \\ ${ }^{1}$ Curso de licenciatura em Ciências Biológicas, Universiade Federal de Campina Grande, \\ Centro de Educação e Saúde, Cuité-PB, Brasil. \\ ${ }^{2}$ Programa de pós Graduação em Biodiversidade, Universidade Federal da Paraíba, Centro de Ciencias \\ Agrárias Areia-PB, Brasil. \\ Email para correspondência: merisoliveira21@gmail.com
}

\begin{abstract}
Resumo
O programa de monitoria é comun nas Instituições de Ensino Superior e tem como principal objetivo a possibilidade de iniciação à docência aos graduandos que dele participam. Pensando na importância dessa atividade, o presente traballho consiste em um relato de experiência a partir da vivência da primeira autora como monitora da disciplina de Botanica Criptogâmica do curso de Ciências Biológicas. Foram realizadas atividades de atendimento extraclasse com os alunos, participação em aulas teóricas e práticas, reuniões para planejarmos o encaminhamento do desenvolvimento da disciplina e pesquisa com os alunos referente as contribuições da monitoria. Dentre as colaborações deste programa para a autora, destacam -se o aprofundamento no campo dos conhecimentos adquiridos tanto pela convivência com os alunos quanto pela troca de saberes, e acompanhamento do planejamento didático metodológico, junto ao professor supervisor. Dessa forma, conlui-se que o programa de monitoria constitui uma oportunidade essencial na formação docente, no apoio ao processo de ensinoaprendizagem dos alunos atendidos e para crescimento e desenvolvimento da produção acadêmica do monitor.
\end{abstract}

Palavras-chave: Botânica Criptogâmica, Formação profissional, Possibilidades.

\section{Abstract / resumen / résumé}

The monitoring program is common in the Institutions of Superiore Teaching has as main objective the possibility of initiation to teaching to the graduating students that participate in it. Thinking about the importance of this activity, the present work consists of an experience report from the experience of the first author as a monitor of the Cryptogamic Botanic discipline of the Biological Sciences course. Extraclass attendance activities were carried out with the students, participation in theoretical 
and practical classes, meetings to plan the development of the discipline and research with the students regarding the contributions of the monitoring. Among the collaborations of this program for the author, we emphasize the deepening in the field of the acquired knowledge, as much by the coexistence with the students as by the exchange of knowledge, and accompaniment of the methodological didactic planning, next to the supervisor professor. Thus, it is concluded that the monitoring program constitutes an essential opportunity in teacher education, in the support to the teaching-learning process of the students served and in the growth and development of the academic production of the monitor

Keywords: Cryptogamic Botany, Professional qualification, Possibilities

\section{Introdução}

A monitoria no ensino superior foi regulamenta no Brasil em 1968, pela Lei Federal $\mathrm{n}^{\circ}$ 5.540, artigo 41, onde instituiu que:

As universidades deverão criar as funções de monitor para alunos do curso de graduação que se submeterem a provas específicas, nas quais demonstrem capacidade de desempenho em atividades técnico-didáticas de determinada disciplina (BRASIL, 1968).

Em seu parágrafo único, a Lei é mais enfática ao afirmar que as "funções de monitor deverão ser remuneradas e consideradas título para posterior ingresso em carreira de magistério superior". Estas condições impostas por lei trazem garantias que amparam o acadêmico, como aponta Souza (2009) ao defender que o ofício da monitoria nos traz benefícios intelectuais e, além disso, é considerada no currículo, a qual pontua para admissão de programas de pós graduação.

De acordo com Frison e Moraes (2010) a monitoria é uma atividade de apoio ao ensino, em que estudantes mais adiantados auxiliam no aprendizado dos colegas em uma determinada disciplina. Dessa forma, o aluno monitor tem a oportunidade de começar a exercer o papel de docente ainda na graduação. Essas considerações acerca da monitoria defendida por Frison e Moraes (2010) se assemelham as de Pereira (2009) quando este afirma que:

Os monitores atuam, por assim dizer, como "professores" tirando dúvidas de seus colegas, auxiliando na resolução de exercícios, contribuindo para a assimilação da matéria ministrada em sala de aula pelo professor, ajudando-os a estudar para as provas, e assim por diante (PEREIRA, 2009, p.3).

Ainda de acordo com Pereira (2009) a figura do aluno monitor está cada vez mais presente no contexto das universidades, possibilitando auxílio aos professores e aos alunos. Este papel de mediador entre professor - aluno - 
conhecimento torna-se fundamental para a construção da identidade profissional do monitor, bem como para a interação social dos envolvidos. Nesse sentido, o monitor desempenha um importante papel de apoio no processo de ensino-aprendizagem, considerando a sobrecarga de trabalho do professor e as lacunas de aprendizagem dos alunos (PEREIRA, 2009).

A monitoria é uma oportunidade de extrema relevância para a apropriação do conhecimento, onde se exige do monitor maior dedicação e aperfeiçoamento nos estudos sobre os conteúdos mais procurados pelos alunos. Atrelado a isto se somam os encontros e discussões sobre as dúvidas dos alunos e a construção da postura docente do monitor enquanto articulador destas discussões.

Desse modo, a monitoria acadêmica possibilita ao monitor o crescimento acadêmico, atuando em atividades educacionais que contribuem para o desenvolvimento da aprendizagem e espírito de liderança desses discentes" (FERNANDES et. al., 2016. p.37).

A disciplina Botânica Criptogâmica é ofertada no primeiro período do curso de Ciências Biológicas da Universidade Federal de Campina Grande (UFCG), do Centro de Educação e Saúde (CES), campus Cuité- PB. É uma disciplina com muitos conceitos novos para os alunos que vem do ensino básico com pouca ou nenhuma informação Botânica. Conforme Santos e Sodré Neto (2016) o ensino de Botânica é uma das áreas da Biologia mais difícil de se compreender, sendo esta colocação também enfatizada por Melo et. al. (2012).

Os cursos de ensino superior exigem mudanças sob a forma de aprender, defendendo a posição crítica e reflexiva dos alunos. A monitoria nesse sentido vem para quebrar a postura passiva dos estudantes e inseri-los em um espaço de socialização, como investigadores do conhecimento, ofertando a oportunidade dos mesmos se posicionar a frente, questionar e buscar sanar as dúvidas sobre os conteúdos incompreendidos em sala de aula.

Diante da importância que a monitoria representa para a academia, considerando também a sua contribuição para a formação docente e para a relação professor-aluno-conhecimento, o presente trabalho consiste em um relato de experiência vivenciado pela primeira autora, a partir da sua 
participação no Programa de Monitoria do CES/UFCG, onde atuou como monitora voluntária da disciplina de Botânica Criptogâmica.

\section{Metodologia}

O presente trabalho tem como base a descrição das atividades que foram desenvolvidas durante todo o período de atuação, que ocorreu no semestre 2015.1, tendo em vista atender os estudantes do primeiro período do Curso de Ciências Biológicas do Centro de Educação e Saúde (CES) da Universidade Federal de Campina Grande (UFCG) na disciplina de Botânica Criptogâmica. Como este trabalho aborda a experiência pessoal da primeira autora durante a sua vivência na monitoria, dados acerca do perfil socioeconômico dos alunos que foram monitorados, assim como outros dados pessoais, não foram levantados.

A disciplina supracitada tem como objetivo proporcionar uma visão integral dos principais grupos de algas, plantas avasculares e plantas vasculares sem sementes; estudo da morfologia, sistemática, biologia e ecologia desses grupos, bem como a seleção de tópicos de interesse para pesquisas puras e aplicadas.

Após a aprovação no processo seletivo de monitoria, inicialmente ocorreram reuniões com o docente da disciplina a fim de planejarmos 0 desenvolvimento da mesma. Nessas reuniões fomos orientados acerca das atividades que deveríamos realizar. Dentre essas atividades estavam: participação em aulas teóricas e práticas e auxilio na preparação destas, como, por exemplo, arrumar os microscópios na bancada e preparar as lâminas com material biológico, e depois recolher, lavar e guardar todo o material, e elaboração de questionários referentes a conteúdos da disciplina. Após o termino do período letivo fomos instigadas a aplicar um questionário de avaliação relativo a participação dos alunos na monitoria a fim de investigar as contribuições desse serviço para os estudantes. Os resultados obtidos por meio desse questionário fizeram parte de um trabalho já publicado em anais de um evento cientifico. 


\section{$3 \quad$ Resultados e discussão}

\subsection{As possibilidades vivenciadas pela monitora}

Através das atividades desenvolvidas (Figura 1), a monitora teve a oportunidade de rever os conteúdos estudados, o que proporcionou mais ganho intelectual e, com isso, mais segurança para monitorar os demais estudantes. Além de estudar esses conteúdos em horários extraclasse, havia ainda o momento das aulas ministradas pelo docente, nas quais a monitora estava presente. Dessa forma, a mesma percebia que, com essas vivências, seu aprofundamento nos conteúdos era inevitável. Além disso, o contato da monitora com os demais alunos resultou em trocas de conhecimentos significativos e na construção de laços de amizades mais profundos. Souza (2009, p. 1) enfatiza que:

A importância da Monitoria nas disciplinas do ensino superior extrapola o caráter de obtenção de um título. Sua importância vai mais além, seja no aspecto pessoal de ganho intelectual do Monitor, seja na contribuição dada aos alunos monitorados e, principalmente, na relação de troca de conhecimentos, durante o programa, entre professor orientador e aluno monitor.
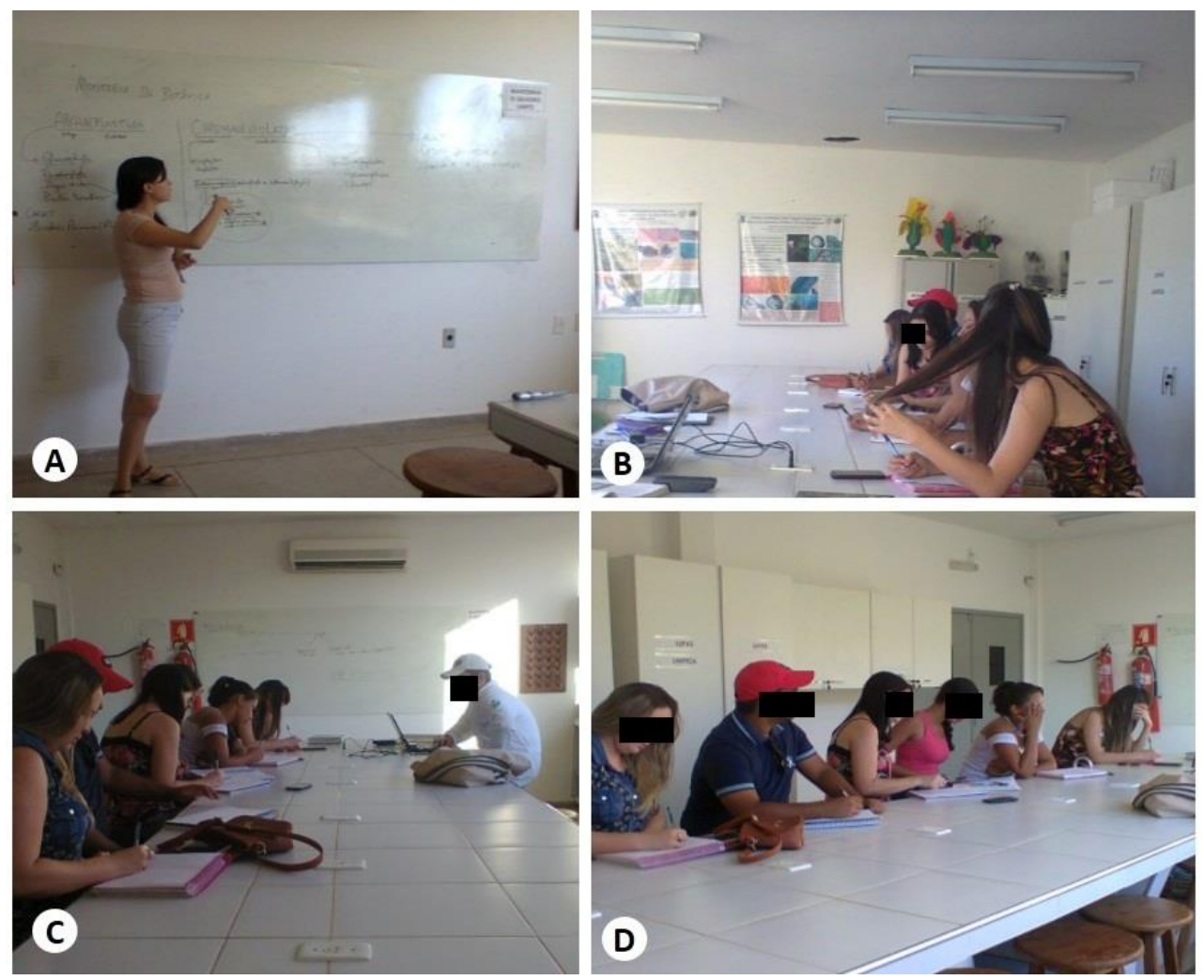

Figura 1. Atendimento de alunos durante a monitoria da disciplina Botânica Criptogâmica, no Laboratorio de Botânica, do Centro de Educação e Saúde (CES). 
Fonte: Arquivo pessoal.

O exercício desta atividade trouxe a monitora a possibilidade de dar os primeiros passos na carreira docente. Assim, a monitoria traz uma excelente oportunidade de antecipação da experiência docente, em particular, no ensino superior. De acordo com Silva e Lacerda (2015) através da monitoria o aluno monitor experimenta os dissabores e as alegrias do que vem a ser a profissão de professor universitário.

Silva et. al. (2016), em sua pesquisa no Centro de Educação e Saúde (CES), para verificar se a monitoria oferecia subsídios para formação docente, observaram que para os estudantes monitores essa atividade implicou em momentos agradáveis e isentos de dissabores, o que pode estimular mais ainda o monitor seguir a carreira docente.

[...]os programas de monitoria contribuem para a formação dos futuros professores, uma vez que os põem em situações que permitem experimentar as vivências de um docente. $O$ monitor, ao auxiliar o professor orientador em uma determinada disciplina, participa do processo de construção do conhecimento de seus colegas tirando dúvidas, revisando os conteúdos, indicando literatura, e ele mesmo também aprende com isso, o que torna o processo favorecedor para todas as partes envolvidas. (SILVA, et al. 2016).

Enquanto monitora, a autora teve a oportunidade de vivenciar, ainda que indiretamente, experiências relacionadas a prática docente, participando do planejamento de aulas práticas, traçando, junto ao docente responsável pela disciplina, estratégias que viessem a contribuir para a melhoria do processo de ensino-aprendizagem, pois os alunos tinham muitas dificuldades com a disciplina de Botânica Criptogâmica.

Participar do planejamento é um ponto extremamtente importante para que o monitor perceba que a profissão docente vai além da sala de aula e da exposição de conteúdos. Por traz da presença do professor, dos alunos e dos conteúdos abordados existe um outro cenário que exige, além do cumprimento da ementa, a habilidade de planejar de maneira que atenda as reais necessidades do professor e dos alunos. Dessa forma, acordo Magalhães, Januário e Maia (2014) enfatizam que:

\footnotetext{
"Para os monitores, a monitoria possibilita um contato próximo com a docência, capacidade de desenvolver suas habilidades didáticopedagógicas, possibilidade de estudar e se aprofundar nos conteúdos para assim repassá-los". (p. 562)
} 
Como complemento, a participação como monitora resultou ainda em resumos relacionados à prática pedagógica, publicados em anais de eventos científicos, conforme o edital PRE (Pró-reitoria de Ensino) no 014/2015, da UFCG, para o processo seletivo de monitores, que aponta como uma das funções do monitor a participação em atividades que propiciem o seu aprofundamento na disciplina, como revisar textos, produzir resenhas bibliográficas e mesmo apresentar trabalhos em encontros acadêmicos. Estas atividades de participação em eventos científicos são essenciais para conhecer a diversidade de práticas educacionais e principalmente por despertar nos monitores 0 incentivo de produções cientificas que são relevantes na construção do currículo e desenvolvimento da escrita.

Lins et al (2009) ao discorrer sobre a importância da monitoria para a formação academica do monitor traz a seguinte reflexão: "As experiências vividas na monitoria acadêmica são marcas que ficarão impressas no intelecto de quem tem o privilégio de vivenciar essa realidade". De fato, a participação da autora no Programa de Monitoria trouxe contribuições significativas para a mesma e, atualmente, a monitoria é a temática investigada em seu Trabalho de Conclusão de Curso (TCC).

\subsection{As contribuições da monitoria vivenciadas pelos alunos}

O monitor não é o único que se beneficia da atividade de monitoria. Os discentes beneficiados encontraram no monitor um suporte em relação à disciplina onde puderam construir conhecimentos junto aos colegas que se encontram na mesma situação, compreendendo e compartilhando os mesmos anseios. Nesse sentido, Magalhães, Januário e Maia (2014, p. 562) destacam "Os discentes também são favorecidos neste processo, uma vez que se sentem mais à vontade para sanar suas dúvidas e fazer questionamentos ao monitor". Por vezes os discentes sentem uma distância entre aluno/professor e bloqueiam a proximidade e a relação entre as partes, implicando em dúvidas não esclarecidas. O monitor, neste aspecto, favorece essa relação de mediador na relação professor-aluno-conhecimento. Neste cenário os alunos se sentem mais à vontade para procurar os monitores. 
Durante a experiência aqui relatada foi possivel perceber a importância pessoa do monitor. Os alunos costumavam ir para as monitorias pelo menos uma vez na semana e, quando se aproximava o dia da prova, o número de estudantes que buscavam esse suporte aumentava. Nisto é reconhecido o êxito do programa. Esta procura em vésperas de provas parece ser uma caracteristica comum entre os alunos em diversas instituições. Guimarães, Santa Rita e Sousa (2016) ao fazerem uma relato de experiência da vivência na monitoria da disciplina de Biologia Celular na Universidade Federal de Goias-Go, revelam que [..] "a procura da monitoria foi realizada principalmente durante as vésperas das avaliações, sendo possível observar que alguns alunos ficavam "desesperados" por não conseguirem entender a disciplina". (GUIMARÃES, SANTA RITA E SOUSA, 2016, p. 939).

Durante o desenvolvimento do programa de monitoria em universidades, existem alunos que negligenciam o suporte didático oferecido pelo monitor e ainda o subutiliza devido as mais diversas circunstâncias. (SILVA; BELO, 2012). Nesse sentido, Assis et. al. (2006, apud MATOSO, 2014) enfatizam que o monitor, por estar em contato direto com alunos, pode vivenciar situações únicas e extraordinárias, como a possibilidade de contribuir com o aprendizado de seus colegas, mas, também, momentâneas desilusões, devido situações em que alugns estudantes podem demonstrar uma conduta inconveniente e desestimuladora.

Fazendo uma breve consideração a cerca da percepção que se teve dos alunos participantes, percebeu-se que uma parcela deles, durante as atividades da monitoria, mostrou-se ativa, buscando, por meio desse suporte, sanarem as suas dúvidas. Notou-se tammbém que os estudantes se sentiam confortáveis para externar suas dúvidas, discutindo os erros e os acertos. Assim o programa mostrou-se eficiente solucionando bloqueios de aprendizagem, do que se pode inferir que as condutas não devem ser generalizadas.

Percebendo uma postura integradora dos alunos dentro da disciplina a monitora decidiu realizar uma pequisa a fim de saber a opinião dos estudantes quanto a contribuição do programa para a sua aprendizagem. Para tanto, aplicou-se, ao final do periodo, um questionário para aqueles que sempre a 
frequentavam. Treze estudantes participaram da pesquisa e os resultados se mostraram positivos, uma vez que todos consideraram importante ter um apoio na disciplina através da figura do monitor (a). Os fragmentos dos discursos dos estudantes atendidos abaixo evidencia a importância que os mesmos atribuíram a monitoria.

"[...]contribuiu muito para o aprendizado, e ajudou no entendimento do assunto". (Aluno 1).

"[...]a monitoria possibilitou uma melhor aprendizagem e entendimento dos assuntos abordados." (Aluno 2).

"[...]ajudou a esclarecer o conteúdo que estava difícil de compreender". (Aluno 3).

"[...]a monitoria era um grande incentivo na busca da compreensão dos assuntos". (Aluno 4).

"[...]sempre me sentia incentivada". (Aluno 5).

Assim, percebeu-se que houve uma construção de confiança, incentivo e apreensão de conhecimento para ambas as partes envolvidas. De forma semelhante Ponte Neto e colaboradores (2012) quando pesquisaram sobre os benefícios da monitoria para os discentes chegaram a conclusão de que esta atividade:

"[...] Gera nos alunos-monitorados um sentimento de auto-confiança e estímulo ao perceber que o monitor, um aluno assim como eles, teve capacidade de desenvolver um conhecimento avançado sobre um determinado assunto, isso os deixa convictos de que também são capazes de atingir um bom nível de conhecimento." (PONTE NETO et al. 2012, p. 3).

\section{Conclusão}

A participação em um programa de monitoria é de suma relevância, principalmente para alunos de licenciaturas que tem a oportunidade de conhecer de perto os procedimentos didáticos pedagógicos da docência e iniciar os primeiros passos desta profissão ainda enquanto estudantes.

Considera-se ainda, a importância da monitoria para a instituição de ensino superior pelas contribuições que essa atividade traz para os demais acadêmicos que desfrutam do apoio dessa atividade através das trocas de saberes, resolução de dúvidas, capacidade de trabalhar em grupo, pela 
aproximação promovida entre professores e alunos, e principalmente as contribuições para aprovação e contra a evasão acadêmica.

A participação em um programa de monitoria interfere ainda na capacitação de futuros profissionais conhecedores dos desafios das profissões tornando-se aptos a desenvolverem suas funções. Estes são os resultados da contribuição da monitoria na construção da personalidade docente, na capacitação de habilidades e competências e produção de conhecimento cientifico, configurando-se em um somatório de benefícios aos envolvidos.

Considera-se, dessa forma, que participar do programa desenvolvendo as funções de monitor (a) é uma experiência que deveria ser vivenciada por todos os alunos das IES (INSTITUIÇÕES DE ENSINO SUPERIOR), não apenas de licenciatura, mas também de outros cursos, uma vez que a monitoria tende a preparar os alunos para enfrentar as mais diversas situações durante sua atuação profissional.

\section{Referências}

ASSIS, F.;BORSATTO, A. Z., SILVA, P. D. D.; PERES, P. L., ROCHA, P. R., LOPES, G. T. . Programa de monitoria acadêmica: percepções de monitores e orientadores. Rev. Enferm. Uerj, 2006, v. 14, n. 3, p. 391-397.

BRASIL. Senado Federal. Lei Federal N․ํ 5540, de 28 de novembro de 1968. $\overline{9.394 / 1996 .}$

Lei de Diretrizes e Bases da Educação Nacional - LDB. Lei N ․o

BARBOSA, M. G.; AZEVEDO, M. E. O.; \& DE OLIVEIRA, M. C. A. Contribuições da monitoria acadêmica para o processo de formação inicial docente de licenciandas do curso de ciências biológicas da FACEDI/UECE. Revista da Snebio, 2014.

FRISON, L. M. B.; MORAES, M. A. C. de. As práticas de monitoria como possibilitadoras dos processos de autorregulação das aprendizagens discentes. Poíesis Pedagógica, v. 8, n. 2, p. 144-158, 2011.

FERNANDES, J.; ABREU, T.A.; DANTAS, A.J.L.; SILVA, A. M.S. Influência da Monitoria Acadêmica no Processo de Ensino e Aprendizagem da Psicologia.

Clínica \& Cultura v.2, n.1, jul-dez, p. 36-43, 2016.

GUIMARÃES, J. B.; SANTA RITA, R. M.; SOUSA, D. B. A vivência como monitor na disciplina de biologia celular. In: Anais do Congresso de Ensino, Pesquisa e Extensão - CONEPE, p. 937 - 940, 2016. 
LINS, L. F.; FERREIRA L. M. C.; FERRAZ L. V.; CARVALHO S. S. G. de. A importância da monitoria na formação acadêmica do monitor. Jornada de ensino, pesquisa e extensão da UFRPE, 9., Recife. Anais... Jepex: UFRPE, 2009. P. 1-2. 2009.

MAGALHÃES, L. D., JANUÁRIO, I. de. S., MAIA, A. K. F. A monitoria acadêmica da disciplina de Cuidados Críticos Para a enfermagem: um relato de experiência. Revista da Universidade Vale do Rio Verde, Três Corações, v. 12, n. 2, p. 556-565. 2014.

MATOSO, L. M. L. A importância da monitoria na formação acadêmica do monitor: um relato de experiência. CATUSSABA, v. 3, n. 2, p. 77-83, 2014.

MELO, E. A; ABREU, F.F; ANDRADE, A. B; ARAÚJO, M. I. O. A aprendizagem de botânica no ensino fundamental: Dificuldades e desafios. Scientia Plena, v. 8, n. 10, p. 8, 2012.

PEREIRA, G. C. A monitoria como auxílio ao processo de ensino aprendizagem: um estudo de caso no curso de ciências contábeis da Universidade Federal de Santa Catarina. 2009. 56 p. Trabalho de Conclusão de Curso (Bacharelado em Ciências Contábeis) - Universidade Federal de Santa Catarina, Florianópolis, 2009.

PONTE NETO, V. F. da; COSTA, M. C. da; BASÍLIO, L. S.; CAMPOS NETO, F. H. Benefícios Conferidos aos Alunos, Monitores e Monitorados, durante as Atividades de Monitoria. In: XII Encontro de Iniciação à Docência da UNIFOR, 2012, Fortaleza. Anais dos Eventos Científicos 2012. 2012.

SANTOS, E.A.V.; SODRÉ NETO. Dificuldades no ensino-aprendizagem de Botânica e possíveis alternativas pelas abordagens de Educação Ambiental e Sustentabilidade. Educação Ambiental em Ação. n.58, 2016.

SILVA, C. B.; LACERDA, A. M. Monitoria na disciplina investigação em psicologia I: um relato de experiência. HUM@N/E: Questões controversas do mundo contemporâneo. v. 9, n. 1, (2015).

SILVA, R. N.; BELO, M. L. M. Experiências e reflexões de monitoria: contribuição ao ensino-aprendizagem. Scientia Plena, v. 8, n. 7, 2012.

SILVA, M. de O. S.; SILVA, C. F. da., NASCIMENTO, F. G. SILVA, J. V. F. da. A monitoria como subsídio para o processo de formação docente, Universidade Federal de Campina Grande, campus de Cuité - PB. In: II Congresso Internacional de Educação Inclusiva II Jornada Chilena Brasileiro de Educação Inclusiva, Campina Grande, 2016, Anais...; Campina Grande, Realize, 2016.

SOUZA, Paulo Rogerio Areias de. A importância da monitoria na formação de futuros professores universitários. In: Âmbito Jurídico, Rio Grande, XII, n. 61, fev 2009. Disponível em: <http://www.ambitojuridico.com.br/site/index.php?n_link=revista_artigos_leitura\&artigo_id=5990>. Acesso em mar 2018. 
UNIVERSIDADE FEDERAL DE CAMPINA GRANDE. Edital Pre no 014/2015 Processo Seletivo de monitores. Disponível em: www.ufcg.edu.br:8080/chamadas/downloads/525218.pdf. Acesso em: 04/01/2017. 